\title{
U.S. Dermatology Faculty Evaluation by Residents: Results of a National Survey
}

\author{
Erica Linnel1 ${ }^{\S, 2}$, Cheryl Nelson ${ }^{\S, 3}$, Scott R. Freeman ${ }^{2}$, David Crockett ${ }^{4}$, Laura Umstattd ${ }^{5}$ and \\ Robert P. Dellavalle,1,2
}

\author{
${ }^{I}$ Denver VA Medical Center, Denver, CO, USA \\ ${ }^{2}$ University of Colorado Denver, School of Medicine, Aurora, CO, USA \\ ${ }^{3}$ University of Nevada School of Medicine, Las Vegas, NV, USA \\ ${ }^{4}$ Cornell University, Ithica, NY, and ${ }^{5}$ University of Texas Medical Branch, Galveston, TX, USA
}

\begin{abstract}
Although the Accreditation Council for Graduate Medical Education (ACGME) requires regular resident evaluation of faculty, little is known about the process. The program directors of 112 ACGME-accredited dermatology residency programs were mailed a twenty-item survey and asked to return a blank copy of any evaluation form(s) used to evaluate faculty at their program. Eighty-seven percent returned the completed survey (97/112) and 48\% (54/112) returned copies of the faculty evaluation forms used. Approximately two-thirds of respondents were residency directors $(63 \%)$ and one-third department chairs or section heads (33\%). Ninety-six percent reported that residents evaluated dermatology faculty, and the vast majority $(92 \%)$ had residents evaluate faculty anonymously. Evaluations were most often a paper form distributed to resident mailboxes (33\%) or an electronic form sent to resident email accounts (29\%). Only 4 programs used different forms to evaluate faculty in different dermatology subspecialties (e.g. dermatopathology $v s$ pediatric dermatology). The most common components of the evaluations asked residents to rate faculty teaching (50/54), to fill in any additional comments about the faculty member (50/54), and to rate faculty availability/accessibility (40/54). Faculty evaluations by residents were most frequently regarded as somewhat important (67\%) or very important (18\%) for faculty promotion. Survey respondents' additional comments cited the increasing importance of faculty evaluations in influencing promotions and improving teaching, the critical necessity for assuring residents' anonymity, and concern regarding the possible negative impact of invalid assessments.
\end{abstract}

Keywords: medical education, faculty evaluation.

\section{INTRODUCTION}

Resident evaluations of faculty remain the most prevalent and consistent method used to assess teaching effectiveness $[1,2]$. Because faculty evaluations enhance teaching and improve faculty performance $[1,3]$ the Accreditation Council for Graduate Medical Education (ACGME) requires the following [4]:

- At least annually, the program must evaluate faculty performance, as it relates to the educational program.

- These evaluations should include a review of the faculty's clinical teaching abilities, commitment to the educational program, clinical knowledge, professionalism, and scholarly activities.

- $\quad$ This evaluation must include at least annual written confidential evaluations by the residents.

Very little is known regarding evaluation form content, specificity and usefulness. The aim of our study was to

*Address correspondence to this author at the VA Medical Center, Dermatology Service, 1055 Clermont Street, \# 165, Denver, CO 80220, USA; Tel: 303-399-8020, Ext. 2475; Fax: 303-393-4686;

E-mail: robert.dellavalle@uchsc.edu

${ }^{\S}$ The first two authors contributed equally to this work; name order was randomly assigned. describe program resident faulty evaluation methods (e.g. frequency, distribution, and anonymity), communication of results, and the perceived importance of these evaluations for faculty promotion.

\section{METHODOLOGY}

\section{Survey Instruments}

This study (protocol 06-0494) was approved by the Colorado Multiple Institutional Review Board. A twenty-item survey was created by investigators addressing the content of faculty evaluation forms (Fig. 1). A dermatoepidemiology lab group composed of 6 people created the survey. The group met in a focus session once per week for nine weeks. The survey was revised each time. The survey was piloted by the program director at the University of Colorado Health Sciences Center, and feedback was utilized to further modify the survey. The survey was voluntary and anonymous. Respondents were informed in an introductory letter that responses would not be individually identified.

\section{Study Population}

Dermatology programs and their directors within the United States were identified from online listings at www.acgme.org/adspublic/default.asp. Program directors of the 112 ACGME 
Please answer the following questions regarding overall dermatology faculty performance evaluations.

1. Do dermatology residents in your program evaluate dermatology faculty?

No (skip to question $\# 18$ )
Yes

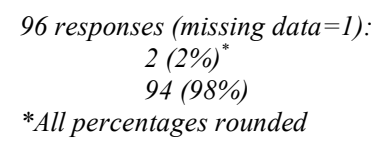

2. How long have dermatology residents evaluated dermatology faculty at your institution?

Less than 1 year
-1 to less than 3 years
3 to less than 5 years
-5 to less than 10 years
- 10 years or longer
Unknown

95 responses (missing data $=2$ ):

$2(2 \%)$

$8(8 \%)$

$15(16 \%)$

$23(24 \%)$

$43(45 \%)$

$4(4 \%)$

3. Who developed the form(s) dermatology residents use to evaluate dermatology faculty?

Department Chair/Section Head
_ Residency Program Director
_ Other Dermatology faculty member
_Unknown
_ Other

97 responses, 140 answers
$38(27 \%)$
$61(44 \%)$
$14(10 \%)$
$7(5 \%)$
$20(14 \%)$

4. Has the form(s) ever been modified?

No (skip to question \#7)
_Yes
__Unknown
95 responses (missing data $=2$ )
$21(22 \%)$
$69(73 \%)$
$5(5 \%)$

5. How many times has the form(s) been modified?

Once
_Twice
_ Three times
_ More than three times
_ Unknown
75 responses (missing data $=22$ )
$14(19 \%)$
$23(31 \%)$
$8(11 \%)$
$14(19 \%)$
$16(21 \%)$

6. Approximately when was the evaluation form(s) last modified?

Within the last year
_One to three years ago
_ More than three years ago
_Unknown
76 responses (missing data $=21$ )
$26(34 \%)$
$36(47 \%)$
$5(7 \%)$
$9(12 \%)$

7. Are identical forms used for all dermatology faculty regardless of their subspecialty within dermatology?

\begin{tabular}{cc} 
The same form is used & 95 responses (missing \\
_Different forms are used & $91(96 \%)$ \\
If yes, how many different evaluation forms are used? & $4(4 \%)$ \\
\hline & $2,2,3,5$
\end{tabular}

8. Which areas of faculty emphasis have separate customized evaluations? (check all that apply)

$\begin{array}{lc}\text {-Medical dermatology } & 3 \\ \text {-Pediatric dermatology } & 2 \\ \text {-Cosmetic dermatology } & 2 \\ \text { - MOHS surgery } & 2 \\ \text { - Dermatopathology } & 4 \\ \text {-Dermatoepidemiology } & 0 \\ \text { - Research faculty } & 0 \\ \text { - Other } & 0\end{array}$

9. How frequently are dermatology residents given the dermatology faculty evaluation form(s)?

\begin{tabular}{|c|c|}
\hline & 97 responses, 98 answers \\
\hline Once per year & $50(51 \%)$ \\
\hline Twice per year & $32(33 \%)$ \\
\hline Three times per year & $3(3 \%)$ \\
\hline Four or more times per year & $8(8 \%)$ \\
\hline Other_ & $5(5 \%)$ \\
\hline \multicolumn{2}{|c|}{$\begin{array}{r}\text { is the faculty evaluation form(s) distributed to dermatology residents at your institution? } \\
97 \text { responses, } 104 \text { answers }\end{array}$} \\
\hline Paper form to residents' mailboxes & $34(33 \%)$ \\
\hline Paper to the residents at a meeting & $11(11 \%)$ \\
\hline Email & $30(29 \%)$ \\
\hline Other & $29(28 \%)$ \\
\hline
\end{tabular}

10. How is the faculty evaluation form(s) distributed to dermatology residents at your institution? 
(Fig. 1) contd.....

11. How are the dermatology faculty evaluation form(s) collected from dermatology residents at your institution?

$\begin{array}{lc} & 97 \text { responses, } 102 \text { answ } \\ \text { Placed into a collection box } & 6(6 \%) \\ \text { Given to a designated staff member } & 45(44 \%) \\ \text { Electronically saved } & 38(37 \%) \\ \text { - Other } & 13(13 \%)\end{array}$

12. Are the dermatology resident evaluations of dermatology faculty completed anonymously?

$\begin{array}{lc} & 95 \text { responses (missing data }=2) \\ \text { Never } & 3(3 \%) \\ \text {-Always } & 87(92 \%) \\ \text { _-Sometimes (please specify when) } & 5(5 \%)\end{array}$

13. Does the evaluated dermatology faculty member receive a summary of the results of the completed evaluations?

$\begin{array}{lc} & 94 \text { responses (missing } \\ \text {-Never } & 4(4 \%) \\ \text {-Always } & 76(81 \%) \\ \text { - Sometimes (please specify when) } & 14(15 \%)\end{array}$

14. Does anyone review the dermatology resident evaluation results with the dermatology faculty member?

$\begin{array}{lc} & 93 \text { responses (missing data }=4) \\ \text { - No (skip to question \#18) } & 21(23 \%) \\ \text { _Yes } & 72(77 \%)\end{array}$

15. Who reviews the dermatology resident evaluation results with the dermatology faculty member? (Check all that apply)

$\begin{array}{lc} & 97 \text { responses (missing } \\ \text {-Department Chair/Section Head } & 59(61 \%) \\ \text { - Residency Program Director } & 33(34 \%) \\ \text {-Other (please specify) } & 5(5 \%)\end{array}$

16. How are the results of the dermatology faculty evaluations discussed with the faculty at your program? (Check all that apply)

$\begin{array}{lc} & 89 \text { responses (missing } \\ \text {-In person } & 72(81 \%) \\ \text {-By e-mail } & 2(2 \%) \\ \text {-By phone } & 2(2 \%) \\ \text {-Other } & 13(15 \%)\end{array}$

17. How important are the dermatology resident evaluations in determining promotion of the dermatology faculty?

\begin{tabular}{lr} 
Very important & 78 responses (missing \\
-Somewhat important & $14(18 \%)$ \\
- Not important & $52(67 \%)$ \\
\hline
\end{tabular}

18. What is your current position?

Chair/Section Head

Residency Program Director

Other

19. How long have you held your current position?

$$
\begin{aligned}
& \text { Less than one year } \\
& \text { - } 1 \text { to less than } 5 \text { years } \\
& 5 \text { to less than } 10 \text { years } \\
& \text { _ } 10 \text { to less than } 20 \text { years } \\
& \text { 20 years or longer }
\end{aligned}
$$

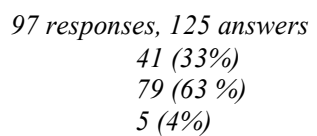

20. Please provide any comments or concerns you have regarding the process of dermatology resident evaluation of dermatology faculty at your institution:

Fig. (1). Questionnaire with results in italics.

accredited dermatology residency programs were asked to complete the twenty-item survey by mail, and return it along with a blank copy of the evaluation form(s) used to evaluate faculty at their program. Surveys and follow-up letters were mailed up to three times to non-responding programs. Data collection began June 1, 2006 and ended October 18, 2006.

\section{Statistical Analysis}

Survey data were entered into a Microsoft Access database and statistical analyses were conducted using SAS version 9.1 (SAS Institute, Cary, NC) software. Evaluation components were compiled (EL and LU) independently, entered into Microsoft Excel spreadsheets and each compo- 
Table 1. Summarized Results, Number of Responses/All Answers (\%)*

\begin{tabular}{|c|c|}
\hline Survey response & $97 / 112(87)$ \\
\hline Blank copy of evaluation form(s) submitted & $54 / 112(48)$ \\
\hline \multicolumn{2}{|l|}{ Survey completed by: } \\
\hline Chair/section head & $41 / 125(33)$ \\
\hline Residency director & $79 / 125(63)$ \\
\hline Other & $5 / 125(04)$ \\
\hline Residents evaluate faculty & $94 / 96(98)$ \\
\hline Same evaluation forms are used for all faculty & $91 / 95(96)$ \\
\hline \multicolumn{2}{|l|}{ Frequency of evaluations per year: } \\
\hline Once & $50 / 98(51)$ \\
\hline Twice & $32 / 98(33)$ \\
\hline Thrice & $3 / 98(03)$ \\
\hline Quarterly & $8 / 98(08)$ \\
\hline Surveys are completed anonymously & $87 / 95(92)$ \\
\hline \multicolumn{2}{|l|}{ Evaluation distribution: } \\
\hline Paper form & $45 / 104(44)$ \\
\hline Email & $30 / 104(29)$ \\
\hline Someone reviews the evaluations with the faculty member & $72 / 93(77)$ \\
\hline \multicolumn{2}{|l|}{ Who reviews evaluations with faculty: } \\
\hline Chair/section head & $59 / 97(61)$ \\
\hline Residency director & $33 / 97(34)$ \\
\hline \multicolumn{2}{|l|}{ Importance of evaluations for promotion: } \\
\hline Very important & $14 / 78(18)$ \\
\hline Somewhat important & $52 / 78(67)$ \\
\hline Not important & $12 / 78(15)$ \\
\hline
\end{tabular}

*Denominators reflect multiple answers possible on select questions.

nent's frequency was tabulated. Discrepancies were resolved by consensus.

\section{RESULTS}

\section{Survey Responses}

A high response rate was obtained: 97 of the 112 selected ACGME-accredited programs returned the completed survey (87\%), Table 1 and Fig (1). Approximately two-thirds of respondents were residency directors $(62 \%)$ and one third were chairs or section heads $(33 \%)$. Only 2 programs reported that residents do not evaluate the dermatology faculty. Ninety-two percent of programs have residents complete the forms anonymously. The distribution of the evaluations to the residents was most often a paper form distributed to resident mailboxes $(33 \%)$ followed by electronic forms sent to resident email accounts $(29 \%)$. Four programs reported using different forms to evaluate faculty in different dermatology subspecialties (e.g. dermatopathology vs pediatric dermatology). Fifteen percent of respondents said that faculty evaluations by residents were not important for faculty promotion; $67 \%$ somewhat important; $18 \%$ very important. Twenty nine respondents filled in additional comments. These comments frequently discussed the importance of the evaluations and guaranteeing anonymity, and issues affecting evaluation validity (Table 2).

\section{Evaluations}

Fifty four respondents returned the faculty evaluation forms used by residents in their programs. The ten most common evaluation components are presented in Table $\mathbf{3}$. The most common components of the evaluations asked residents to rate faculty teaching (50/54), to fill in any additional comments about the faculty member $(50 / 54)$, and to rate faculty availability/accessibility (40/54).

\section{DISCUSSION}

This study demonstrates that residents anonymously evaluate dermatology faculty in almost all dermatology programs without consideration of faculty subspecialty within dermatology. The majority of respondents identified these evaluations as somewhat or very important $(85 \%)$ for determining faculty promotion.

Anonymity concerned many respondents. Some stated that residents might fear retribution for rating a teacher poorly, especially in programs with a smaller numbers of residents. Indeed, previous research has shown that faculty evaluation outcomes differ when performed openly vs anonymously, and that anonymous evaluations demonstrate more internal consistency [5].

A practical, task-oriented approach has been suggested for promoting program evaluation compliance with require- 


\section{Table 2. Additional Comments Regarding the Process of Dermatology Resident Evaluation of Dermatology Faculty}

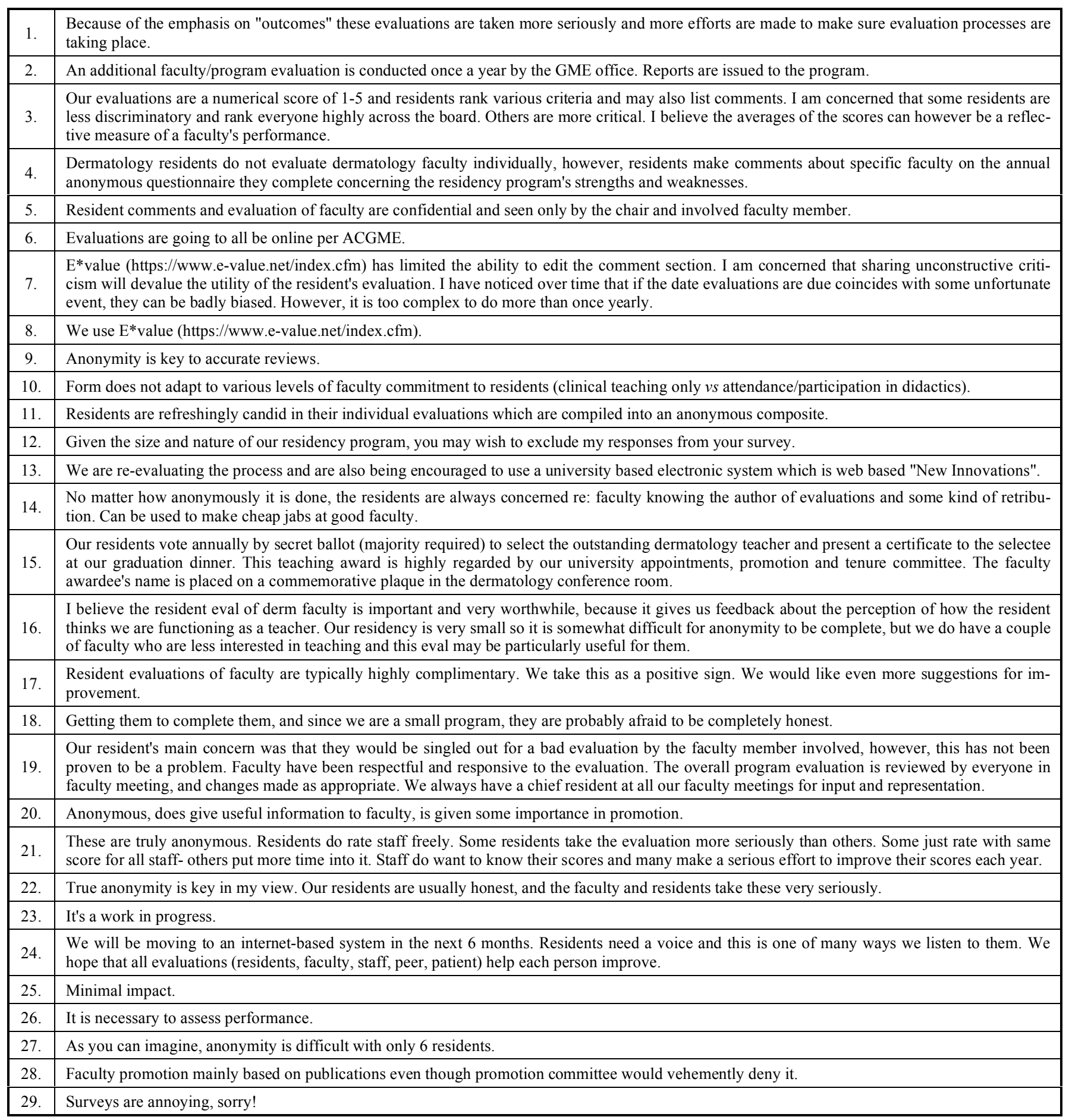

ments for faculty evaluation [6]. Such an approach includes attention to evaluation needs, methods, focus, documentation, and result presentation to key constituents. Faculty and resident involvement in developing the evaluation process at each step will better assure successful outcomes. Dermatology residents cite a lack of mentoring, role models, and career guidance as reasons for losing interest in an academic dermatology career [7]. Canadian dermatology residents have expressed the desire for more teaching and mentoring from faculty [8], and US dermatology residents reported greater satisfaction with more faculty involvement $[9,10]$.
Faculty evaluations carefully exploring resident perceived deficiencies may foster improvement in these areas.

Internet portals may make evaluation more user-friendly and ACGME requirement compliance easier. Twenty nine percent distributed evaluation forms to residents using email while $26 \%$ used a web-based evaluation system like E*Value (https://www.e-value.net/index.cfm) or New Innovations (http://www.new-innov.com/) for the distribution and collection of the forms. Web-based evaluation systems can offer anonymity with greater convenience while preserving high response rates $[11,12]$. 
While our study provides one of the most expansive descriptions of resident evaluation of faculty in the literature, it was nonetheless limited by $48 \%$ of respondents returning the actual forms residents use to evaluate dermatology faculty. Resident evaluations of faculty provide valuable feedback (that influences teaching and promotion) to faculty and residency program leaders. Current evaluations however might benefit from better tailoring to faculty subspecialization; to provide better feedback evaluations should be specific to faculty subspecialty (e.g. dermatopathology, medical dermatology, Mohs surgey, pediatric dermatology, dermatoepidemiology, cutaneous biology research, dermatoepidemiology, procedural dermatology, etc). Faculty evaluations would also benefit from more uniform assessment of faculty enthusiasm and professionalism, subjects addressed by a minority $(48 \%$ and $39 \%$ respectively) of the evaluation forms we received.

Our study was also limited to programs in the USA; further studies might compare these practices with resident evaluation of faculty in other countries. Further work should also examine evaluation practices from the perspective of the faculty and residents involved.

Table 3. Frequency of Evaluation Components

\begin{tabular}{|c|c|}
\hline Evaluation Component & Number (\%) \\
\hline \hline Teaching & $50(93)$ \\
\hline Other comments & $50(93)$ \\
\hline Availability/Accessibility & $40(74)$ \\
\hline Knowledge & $37(69)$ \\
\hline Patient Care/Clinical Skill & $32(59)$ \\
\hline Role Model & $31(57)$ \\
\hline Feedback & $30(56)$ \\
\hline Enthusiasm & $26(48)$ \\
\hline Professionalism & $21(39)$ \\
\hline Communication Skills & $19(35)$ \\
\hline
\end{tabular}

\section{CONCLUSIONS}

U.S. dermatology residents commonly evaluate their faculty members. These evaluations influence faculty promotion and affect teaching, and require resident anonymity to best assure valid assessments.

\section{ABBREVIATIONS}

ACGME $=$ Accreditation Council for Graduate Medical Education

\section{ACKNOWLEDGEMENTS}

We thank Sylvia Brice, MD, for help developing the survey and Lisa M. Schilling, MD, for comments on the manuscript. This study was supported by grant T32 ARO7411 from the National Institutes of Health, Bethesda, MD (Dr. Freeman) and grant K-07CA92550 the National Cancer In- stitute Bethesda, MD (NCI) (Dr. Dellavalle), and the Department of Dermatology, University of Colorado Denver, School of Medicine.

Dr. Dellavalle had full access to the data and takes responsibility for its integrity and the accuracy of the analysis. Preliminary results were presented in poster format at the $65^{\text {th }}$ annual meeting of the American Academy of Dermatology, Washington, DC, February 2-6, 2007. Final results were presented at the Dermatology Teachers Exchange Group Meeting at the $66^{\text {th }}$ Annual Meeting of the American Academy of Dermatology in San Antonio, Texas, on Friday February $1,2008$.

\section{Authors' Contribution}

All authors revised the manuscript and approved the final version submitted. Additionally

EL analyzed data.

CN developed the survey, collected and analyzed data and wrote the initial draft.

SRF developed the survey, collected and analyzed data

DC developed the survey, collected and entered data.

$\mathbf{L U}$ analyzed data.

RPD developed the survey, conceived and supervised the study.

\section{REFERENCES}

[1] Shea JA, Bellini LM. Evaluations of clinical faculty: the impact of level of learner and time of year. Teach Learn Med 2002; 14: 8791.

[2] Tortolani AJ, Risucci DA, Rosati RJ. Resident evaluation of surgical faculty. J Surg Res 1991; 51: 186-91.

[3] Maker VK, Lewis MJ, Donnelly MB. Ongoing faculty evaluations: developmental gain or just more pain? Curr Surg 2006; 63: 80-4.

[4] Accreditation Council for Graduate Medical Education. Chicago, IL: ACGME Headquarters. Available at http://www.acgme. org/. Accessed October 12, 2007.

[5] Alfonso NM, Cardozo LJ, Mascarenhas OA, Aranha AN, Shah C. Are anonymous evaluations a better assessment of faculty teaching performance? A comparative analysis of open and anonymous evaluation processes. Fam Med 2005; 37: 43-7.

[6] Musick DW. A conceptual model for program evaluation in graduate medical education. Acad Med 2006;81:759-65.

[7] Reck SJ, Stratman EJ, Vogel C, Mukesh, BN. Assessment of residents' loss of interest in academic careers and identification of correctable factors. Arch Dermatol 2006; 142: 855-858.

[8] Freiman A, Barzilai DA, Barankin B, Natsheh A, Shear NH. National Appraisal of Dermatology Residency Training. Arch Dermatol 2005; 141: 1100-1104.

[9] Webb JM, Rye B, Fox L, Smith SD, Cash, J. State of dermatology training: The residents' perspective. J Am Acad Dermatol 1996; 34: 1067-71.

[10] Freeman SR, Greene RE, Kimball AB, et al. Training Satisfaction and Mentoring: US Senior Dermatology Resident Survey Results from a National Conference in 2005 and 2006. Arch Dermatol; In press.

[11] Blum JM, Kheterphal S, Tremper KK. A comparison of anaesthesiology resident and faculty electronic evaluations before and after implementation of automated electronic reminders. J Clin Anesth 2006; 18: 264-7.

[12] D'Cunha J, Larson CE, Maddaus MA, Landis GH. An Internetbased evaluation system for a surgical residency program. J Am Coll Surg 2003; 196: 905-10. 